Abstracta Iranica

Revue bibliographique pour le domaine irano-aryen

Volume 34-35-36 | 2017

Comptes rendus des publications de 2011-2013

\title{
Touraj Daryaee (ed.). The Oxford Handbook of Iranian History
}

\section{Barbara Kaim}

\section{OpenEdition}

1 Journals

\section{Édition électronique}

URL : http://journals.openedition.org/abstractairanica/41984

DOI : 10.4000/abstractairanica.41984

ISSN : 1961-960X

Éditeur :

CNRS (UMR 7528 Mondes iraniens et indiens), Éditions de l'IFRI

Référence électronique

Barbara Kaim, «Touraj Daryaee (ed.). The Oxford Handbook of Iranian History », Abstracta Iranica [En ligne], Volume 34-35-36 | 2017, document 5, mis en ligne le 30 juillet 2017, consulté le 03 octobre 2020. URL : http://journals.openedition.org/abstractairanica/41984 ; DOI : https://doi.org/10.4000/ abstractairanica.41984

Ce document a été généré automatiquement le 3 octobre 2020.

Tous droits réservés 


\title{
Touraj Daryaee (ed.). The Oxford Handbook of Iranian History
}

\author{
Barbara Kaim
}

\section{RÉFÉRENCE}

Touraj Daryaee (ed.). The Oxford Handbook of Iranian History. New York, Oxford University Press, 2012, 432 p.

1 Ce volume, qui fait partie d'une série de manuels édités par Oxford University Press, est présenté dans l'Introduction comme « une étude complète du monde iranien (de l'Oxus à l'Euphrate) et son histoire, allant au-delà des frontières de l'État-nation moderne » de la préhistoire aux premières années du XXI ${ }^{e}$ siècle. La tâche n'était pas facile, mais le résultat est largement satisfaisant. Bien que les deux premiers chapitres du volume (« The Iranian Plateau from Paleolithic Times to the Rise of the Achaemenid Empire » et « The Elamites » concernent des périodes antérieures à l'histoire " iranienne », leur inclusion peut se justifier par le désir de présenter le cadre géographique et le passé culturel de la région dans laquelle les tribus iraniennes s'installent plus tard. On note une grande diversité parmi les 16 chapitres du volume qui varient considérablement dans leur approche méthodologique et par la profondeur de la discussion ; ainsi certaines présentations des événements politiques d'une période sont trop simplifiées, tandis que d'autres contributions sont précieuses pour la reconstruction de l'histoire iranienne. À côté des chapitres concernant l'histoire des empires iraniens préislamiques (chapitre 4-7), ce sont certainement les chapitres 8 («Iran in the Early Islamic Period »), 12 (« The Safavids in Iranian History ») et 15 (" The Pahlavi Era »). Comme l'exige le format de la collection, le texte est dépourvu de notes de bas de pages et de références, mais chaque chapitre se termine par une bibliographie de longueur variable, de 15 à 50 titres. 


\section{AUTEURS}

BARBARA KAIM

Université de Varsovie 